Supporting Information:

\title{
Inorganic-ligand quantum dots meet inorganic-ligand semiconductor nanoplatelets: a promising fusion to construct all-inorganic assembly
}

Yunfeng Shi, ${ }^{\text {abc }}$ Sung Jun Lim, ${ }^{\mathrm{c}}$ Liang Ma, ${ }^{\mathrm{c}}$ Ning Duan, ${ }^{\mathrm{ab}}$ Xin Yan,,${ }^{\mathrm{ab}}$ Xiaole Tang, ${ }^{\mathrm{a}}$

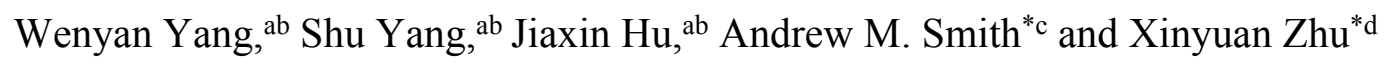

${ }^{a}$ School of Chemistry and Chemical Engineering, Anyang Normal University, Anyang 455000, People's Republic of China.

${ }^{b}$ Henan Province Key Laboratory of $\quad$ New Optoelectronic Functional Materials, Anyang Normal University, Anyang 455000, People's Republic of China.

${ }^{\mathrm{c}}$ Department of Bioengineering, University of Illinois at Urbana-Champaign, Urbana, Illinois 61801, United States.

${ }^{d}$ School of Chemistry and Chemical Engineering, Shanghai Jiao Tong University, 800 Dongchuan Road, Shanghai 200240, People's Republic of China.

E-mail: shiyunfeng2009@gmail.com (Y. Shi), smi@illinois.edu (A. Smith) and xyzhu@sjtu.edu.cn (X.Zhu). 


\section{Peak assignment for the FT-IR spectra (figure 1c)}

CdS QDs capped with organic ligands in hexane: IR $\left(\mathrm{cm}^{-1}\right), 3447\left(v_{\mathrm{s} \mathrm{NH}}\right), 3008(v$ $\mathrm{NH}), 2958\left(v_{\mathrm{CH} 3}\right), 2925\left(v_{\mathrm{as} \mathrm{CH} 2}\right), 2854\left(v_{\mathrm{s} \mathrm{CH} 2}\right), 1711\left(v_{\mathrm{s} \mathrm{COOH}}\right.$, from OA $), 1632\left(\delta_{\mathrm{NH} 2}\right)$, $1602\left(\delta_{\mathrm{NH}}\right)$. All the peaks can be assigned to the OLA and OA organic ligands.

CdS/S- QDs in NMF: IR $\left(\mathrm{cm}^{-1}\right), 3421\left(v_{\mathrm{s} \mathrm{NH}}\right), 3075\left(v_{\mathrm{NH}}\right), 2945\left(v_{\mathrm{as}} \mathrm{CH} 2\right.$, from $\mathrm{NMF}), 2886\left(v_{\mathrm{s} \mathrm{CH}}\right), 1667\left(\delta_{\mathrm{NH} 2}\right)$. All the peaks can be assigned to the NMF solvent and $\left(\mathrm{NH}_{4}\right)_{2} \mathrm{~S}$.
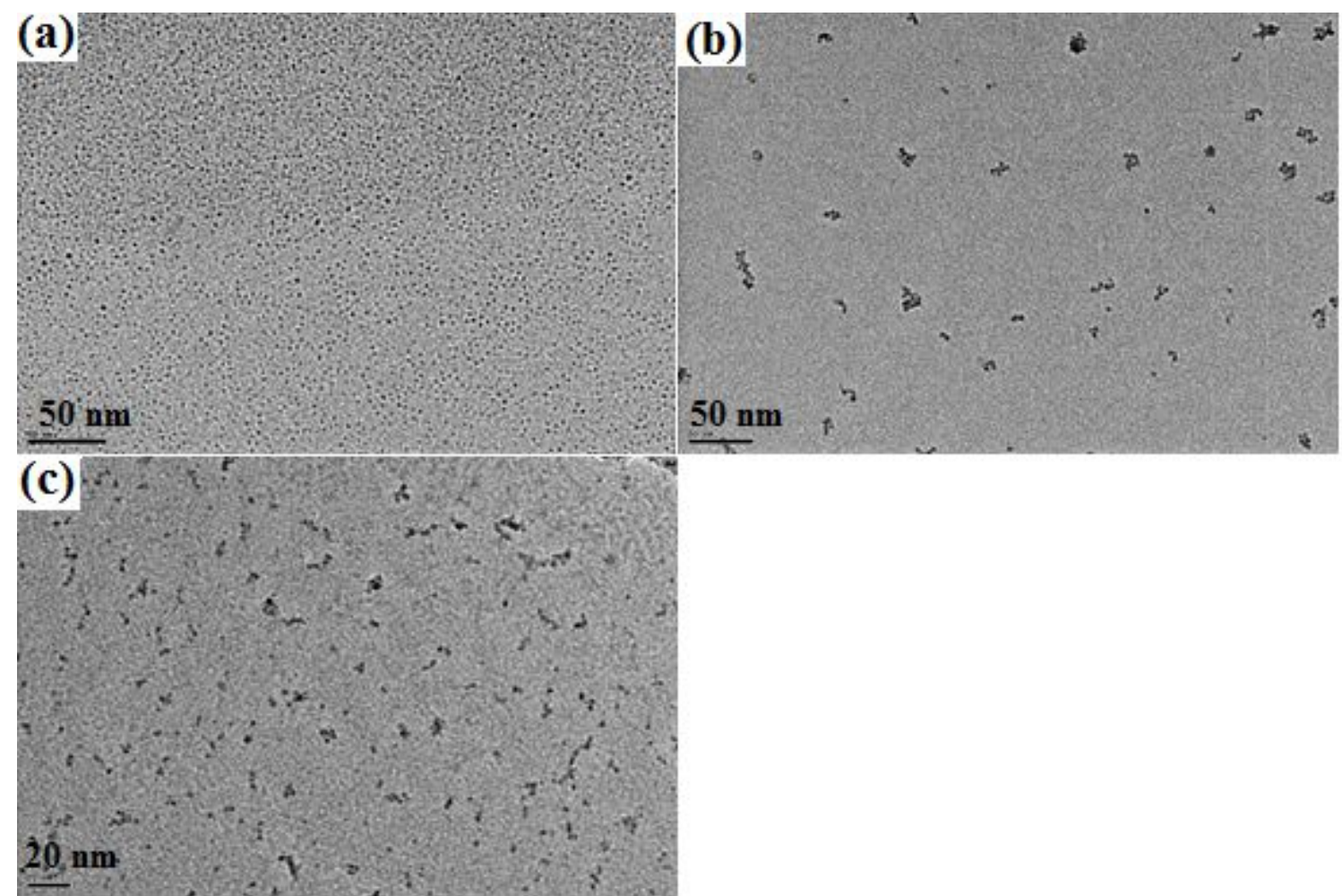

Figure S1. TEM images of (a) CdS QDs, (b) CdS/S2- QDs and (c) $\mathrm{CdS} / \mathrm{Cd}^{2+} \mathrm{QDs}$.

Figure S1 shows the TEM images of $\mathrm{CdS}$ QDs, CdS/S ${ }^{2-} \mathrm{QDs}$ and $\mathrm{CdS} / \mathrm{Cd}^{2+} \mathrm{QDs}$, respectively. The sizes of CdS QDs in different stages are all about $3.3 \mathrm{~nm}$. 

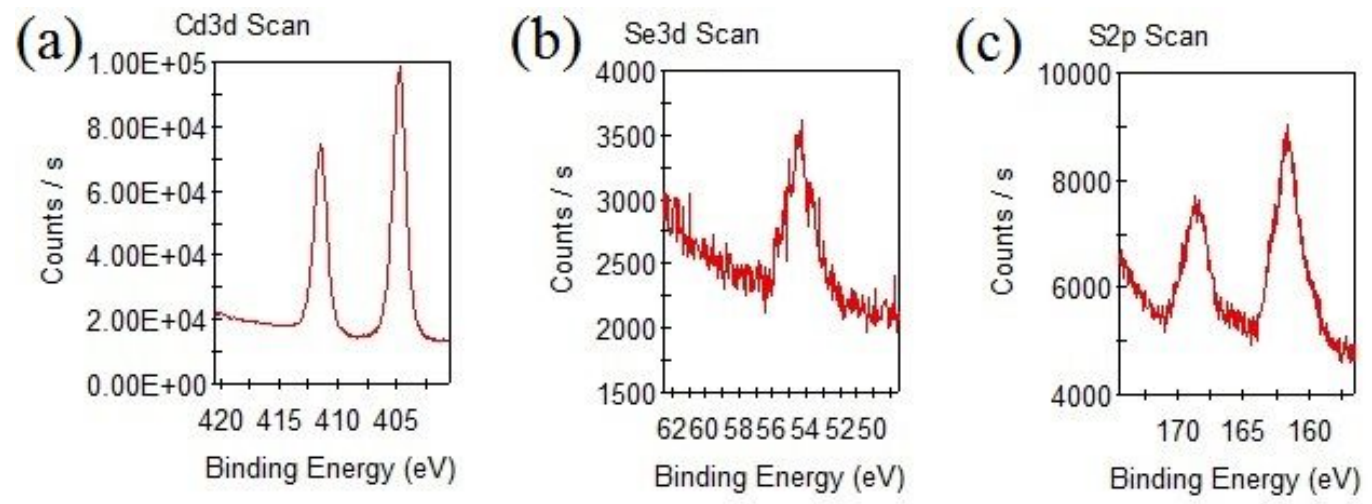

Figure S2. XPS signal regions and the peak assignments for Cd 3d (a), Se 3d (b) and S 2p (c) of CdS QD/CdSe/CdS NPLs in hexane.

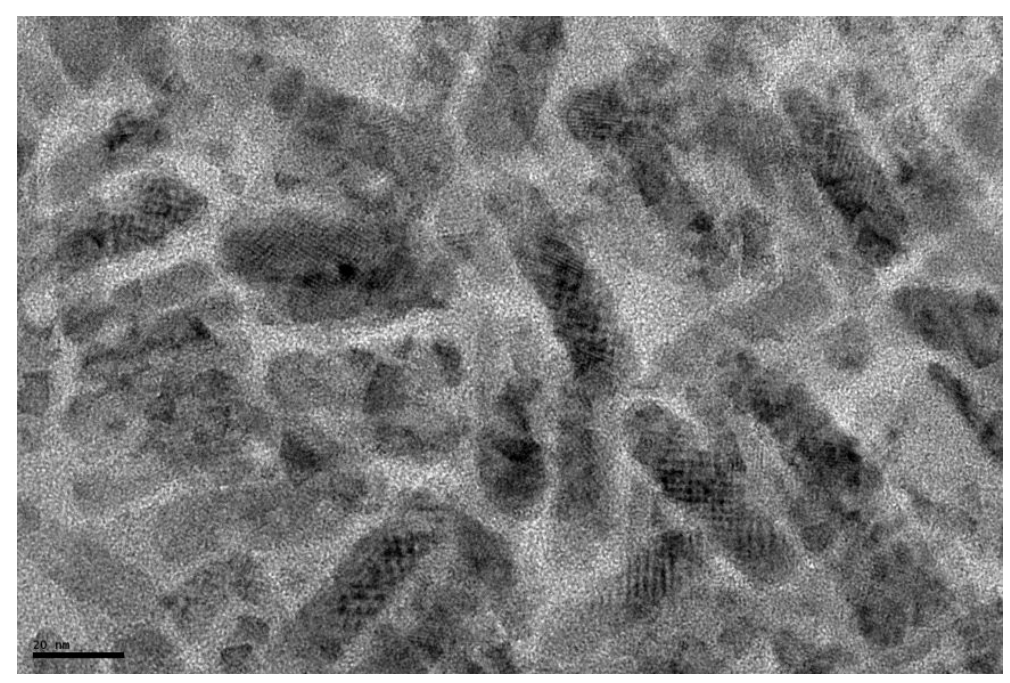

Figure S3. HR-TEM image of CdS QD/CdSe/CdS NPLs in hexane. The scale bar is $20 \mathrm{~nm}$. 


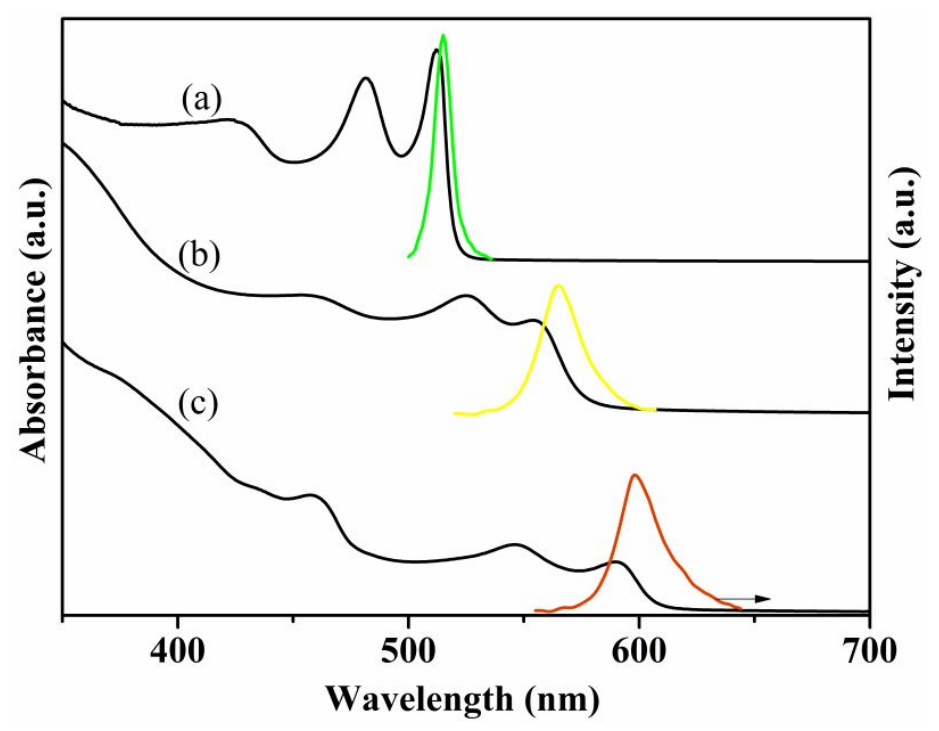

Figure S4. UV-Vis and PL spectra of CdSe NPLs (a), CdSe/S ${ }^{2-}$ NPLs in NMF (b) and CdS QD/CdSe NPLs in NMF (c).

The absorption peaks of CdSe NPLs are located at $481 \mathrm{~nm}$ (light hole state, LH) and $512 \mathrm{~nm}$ (heavy hole state, $\mathrm{HH}$ ), as shown in Figure S4. After being capped by $\mathrm{S}^{2-}$, their absorption peaks shift to $525 \mathrm{~nm}(\mathrm{LH})$ and $555 \mathrm{~nm}(\mathrm{HH})$. When CdSe/S- NPLs fuse with $\mathrm{CdS} / \mathrm{Cd}^{2+}$ QDs, the absorption peaks of the resulting CdS QD/CdSe NPLs locate at $547 \mathrm{~nm}$ and $590 \mathrm{~nm}$. Figure S4 also shows the emission spectra of CdSe NPLs, CdSe/S2- NPLs in NMF and CdS QD/CdSe NPLs in NMF emitting at $515 \mathrm{~nm}$, $565 \mathrm{~nm}$ and $598 \mathrm{~nm}$, respectively.

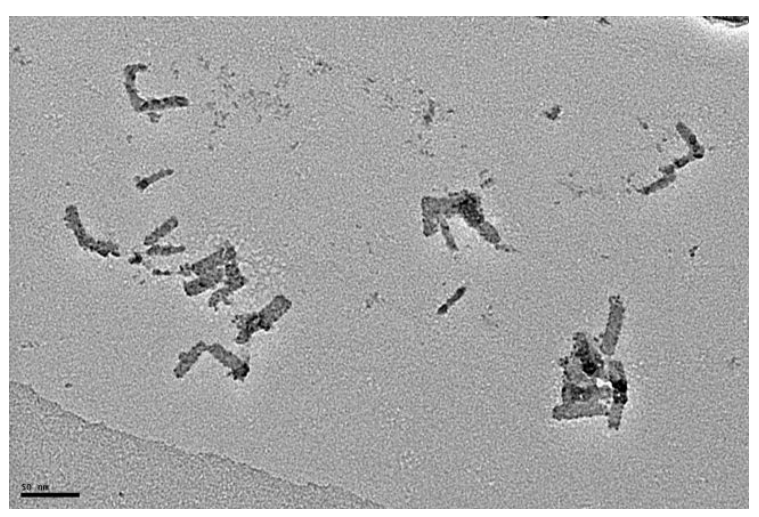

Figure S5. TEM images of CdS QD/CdSe NPLs in NMF. The scale bar is $50 \mathrm{~nm}$. 


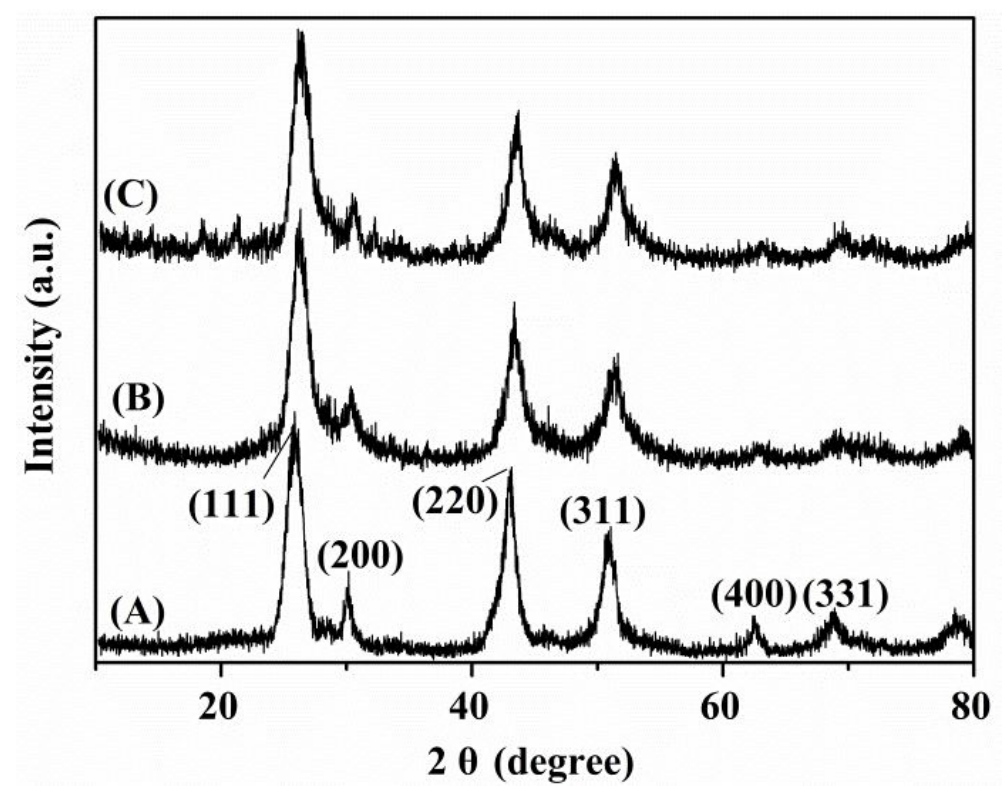

Figure S6. XRD patterns of CdSe/CdS NPLs (A), CdS QD/CdSe/CdS NPLs in NMF (B) and in hexane (C).

The XRD patterns of CdSe/CdS NPLs and CdS QD/CdSe/CdS NPLs are displayed in figure S6. The characteristic diffraction peaks (figure S6A) at $25.9^{\circ}(111)$, $30.2^{\circ}(200), 43.2^{\circ}(220), 51.1^{\circ}(311), 62.4^{\circ}(400)$, and $68.9^{\circ}(331)$ correspond to lattice spacings from six crystallographic planes in CdSe/CdS NPLs with a zinc blende crystal structure. After the fusion of $\mathrm{CdS} / \mathrm{Cd}^{2+} \mathrm{QDs}$ and $\mathrm{CdSe} / \mathrm{CdS} / \mathrm{S}^{2-} \mathrm{NPLs}$, the diffraction peaks of CdS QD/CdSe/CdS NPLs are shifted to higher, as shown in figure S6B,C. 


\section{Synthesis and Method:}

\section{Chemicals}

Sodium myristate $\left(\mathrm{CH}_{3}\left(\mathrm{CH}_{2}\right)_{12} \mathrm{COONa}, 99+\%\right)$, sulfur $(\mathrm{S}, 99.5+\%)$, cadmium oxide $(\mathrm{CdO}, 99.99+\%)$, cadmium acetate $\left(\mathrm{Cd}(\mathrm{Ac})_{2}, 99.99+\%\right)$, cadmium acetate dehydrate $\left(\mathrm{Cd}(\mathrm{Ac})_{2} \cdot 2 \mathrm{H}_{2} \mathrm{O}, 98 \%\right.$ ), selenium powder ( $\mathrm{Se}, \sim 100$ mesh, 99.99\%), sodium sulfide nonahydrate $\left(\mathrm{Na}_{2} \mathrm{~S} \cdot 9 \mathrm{H}_{2} \mathrm{O}, 98+\%\right)$ and ammonium sulfide $\left(\left(\mathrm{NH}_{4}\right)_{2} \mathrm{~S}, 40-48\right.$ wt.\% in $\mathrm{H}_{2} \mathrm{O}$ ) were purchased from Sigma-Aldrich. 1-octadecene (ODE, 90\% tech.), oleic acid (OAc, 90\% tech.) and oleylamine (OLA, 80-90\% C18-content) were purchased from Acros Organics. $N$-methylformamide (NMF, 99+\%) was obtained from Tokyo Chemical Industry. Chloroform, hexane, methanol, ethanol, ethyl acetate and acetone were purchased from Fisher Scientific.

\section{Preparation of cadmium myristate precursor}

$3.13 \mathrm{~g}$ sodium myristate was dissolved in $250 \mathrm{~mL}$ methanol and then $1.06 \mathrm{~g}$ cadmium acetate dihydrate dissolved in $40 \mathrm{~mL}$ methanol was dropwise added. After finishing addition, the mixture was further stirred for $30 \mathrm{~min}$. The resulting white precipitate was filtered and washed with methanol for twice and dried for $12 \mathrm{~h}$ under vacuum.

\section{Nanomaterial synthesis}

\section{(A) CdS QDs synthesis}

CdS QDs were synthesized using methods of Cao et $\mathrm{al}^{[1,2]}$ with minor modifications. $0.2 \mathrm{mmol}$ cadmium myristate, $0.1 \mathrm{mmol} \mathrm{S}, \quad 0.0375 \mathrm{mmol}$ 
2,2'-dithiobisbenzothiazole and 6.3 $\mathrm{mL}$ ODE were mixed in a 50-mL three-neck flask. The mixture was degassed at room temperature for 10 minutes and then $120{ }^{\circ} \mathrm{C}$ for 2 hours to further remove water. The mixture was then heated to $240{ }^{\circ} \mathrm{C}$ under argon and kept for $2 \mathrm{~h}$. After that, $1 \mathrm{~mL}$ oleic acid was added dropwise to stabilize the QDs. The resulting QDs were precipitated by acetone and methanol and then redispersed in hexane.

\section{(B) CdSe NPLs synthesis}

CdSe NPLs were prepared according to literature methods ${ }^{[3-6]}$. In a typical synthesis, $0.6 \mathrm{mmol} \mathrm{CdO}, 1.2 \mathrm{mmol}$ oleic acid and $15 \mathrm{~mL}$ ODE were mixed in a 50 $\mathrm{mL}$ two-neck flask and heated to $250^{\circ} \mathrm{C}$ under argon for $2 \mathrm{~h}$ until the mixture became clear and colorless due to the formation of cadmium oleate. The solution was cooled to $130{ }^{\circ} \mathrm{C}$ and then $0.6 \mathrm{mmol} \mathrm{Se}$ powder was added. Then the temperature was quickly heated up to $240{ }^{\circ} \mathrm{C}$. When the temperature reached $190{ }^{\circ} \mathrm{C}, \mathrm{Cd}(\mathrm{Ac})_{2}(0.6$ mmol) was swiftly added into the mixture to initiate NPL growth. The mixture was kept at $240{ }^{\circ} \mathrm{C}$ for $10 \mathrm{~min}$. When it was cooled to $185^{\circ} \mathrm{C}, 1 \mathrm{~mL}$ oleic acid was added. The reaction yielded CdSe NPLs with the first exciton absorption peak at $510 \mathrm{~nm}$. The CdSe NPLs were purified by adding ethanol containing tri-n-butyl phosphine and subsequent centrifugation at 5,000 r/min. Finally, pure NPLs were redispersed in hexane.

(C) Core/shell CdSe/CdS NPLs synthesis 
Atomic layer deposition protocol was used to layer-by-layer grow CdS shells on purified CdSe NPLs. In a typical reaction, $2 \mathrm{~mL}$ CdSe NPLs in hexane with an absorbance of 4 at the lowest energy excitonic peak was added to $2 \mathrm{~mL}$ $N$-methylformamide (NMF) containing $20 \mu \mathrm{L}\left(\mathrm{NH}_{4}\right)_{2} \mathrm{~S}(40-48 \%)$ solution. The mixture was gently stirred for 1-2 min until the complete phase transfer of NPLs to NMF phase. After phase seperation, the bottom phase was washed with hexane twice and then precipitated by ethyl acetate. $\mathrm{S}^{2-}$ coated NPLs were redispersed in $2 \mathrm{~mL}$ $\mathrm{NMF}$ and $50 \mu \mathrm{L} \mathrm{Cd}(\mathrm{Ac})_{2}$ in $\mathrm{NMF}(0.1 \mathrm{M})$ was added to get a monolayer of CdS shell on the NPL surface. After 5 minutes, NPLs were isolated from the excess Cd ions by precipitation with ethyl acetate. These NPLs were redispersed in NMF, and thus the first monolayer of CdS on CdSe NPLs was completed. To grow x monolayers of CdS, the above step should be repeated $\mathrm{x}$ times. The final CdSe/CdS core/shell NPLs were transferred back to hexane phase by adding OA and OLA. After complete phase transfer and purification by precipitation with excess methanol, pure $\mathrm{CdSe} / \mathrm{CdS}$ core/shell NPLs were redispersed in hexane.

\section{(D) Synthesis of $\mathrm{CdS} / \mathrm{Cd}^{2+} \mathrm{QDs}$ by atomic layer deposition}

Into a $50 \mathrm{~mL}$ reaction flask, $1 \mathrm{~mL}$ CdS QDs in hexane $(29.3 \mathrm{nmol})$ was added to 6 mL N-methylformamide (NMF) solution containing $5 \mu \mathrm{L}\left(\mathrm{NH}_{4}\right)_{2} \mathrm{~S}(40-48 \%)$ under $\mathrm{Ar}$ atmosphere. After ligands exchange taking place, CdS QDs were transferred from hexane phase into NMF phase that became yellow. The resulting CdS/S- QDs in polar NMF phase were washed twice with hexane and then QDs were precipitated with acetonitrile. The precipitates were dispersed into $6 \mathrm{~mL}$ NMF. Then $66 \mathrm{mg}$ 
$\mathrm{Cd}(\mathrm{Ac})_{2}$ in $3 \mathrm{~mL}$ NMF were added and the solution were vigorously stirred for 3 days to get $\mathrm{CdS} / \mathrm{Cd}^{2+}$ QDs. QDs were precipitated with ethyl acetate and dispersed in $6 \mathrm{~mL}$ NMF followed by filtering through a $0.2 \mu \mathrm{m}$ PTFE filter.

\section{(E) Synthesis of CdSe/CdS/S2- NPLs}

Into a $50 \mathrm{~mL}$ two-neck reaction flask, $1 \mathrm{~mL}$ of a solution of CdSe/CdS NPLs in hexane $(0.08 \mathrm{nmol})$ was added to $8 \mathrm{~mL} \mathrm{NMF}$ solution containing $120 \mathrm{mg} \mathrm{Na}_{2} \mathrm{~S} \cdot 9 \mathrm{H}_{2} \mathrm{O}$ under Ar atmosphere. After ligands exchange, CdSe/CdS NPLs were transferred from hexane phase into NMF phase in the form of $\mathrm{CdSe} / \mathrm{CdS} / \mathrm{S}^{2-} \mathrm{NPLs}$. NPLs were washed twice with hexane and precipitated with ethyl acetate. The precipitates were dispersed into $4 \mathrm{~mL}$ NMF.

\section{(F) Fusion of $\mathrm{CdS} / \mathrm{Cd}^{2+}$ QDs and $\mathrm{CdSe} / \mathrm{CdS} / \mathrm{S}^{2-}$ NPLs}

$150 \mu \mathrm{L}$ NMF solution of $\mathrm{CdS} / \mathrm{Cd}^{2+}$ QDs $(0.420 \mathrm{nmol})$ was added into a $4 \mathrm{~mL}$ vial and sonicated for 20 seconds. $600 \mu \mathrm{L}$ NMF solution of $\mathrm{CdSe} / \mathrm{CdS} / \mathrm{S}^{2-}$ NPLs $(0.007$ nmol) was added under vigorously stirring. The mixture was stirred for $6 \mathrm{~h}$ before measurement, resulting into the fusion of $\mathrm{CdS} / \mathrm{Cd}^{2+} \mathrm{QDs}$ and $\mathrm{CdSe} / \mathrm{CdS} / \mathrm{S}^{2-} \mathrm{NPLs}$. The final product was called as CdS QD/CdSe/CdS NPLs. The CdS QD/CdSe/CdS NPLs were transferred to organic phase by adding oleylamine $(\sim 100 \mu \mathrm{L})$ and oleic acid $(\sim 100 \mu \mathrm{L})$ in hexane. After complete phase transfer, the hexane phase was purified by precipitation with ethanol. Finally, the $\mathrm{CdS} \mathrm{QD} / \mathrm{CdSe} / \mathrm{CdS}$ NPLs were dispersed in hexane, resulting into CdS QD/CdSe/CdS NPLs in hexane. 


\section{(G) Synthesis of CdSe/S2- NPLs}

In a $50 \mathrm{~mL}$ two-neck reaction flask, $0.2 \mathrm{~mL}$ of a solution of CdSe NPLs in hexane $(0.1 \mathrm{nmol})$ was diluted with $10 \mathrm{~mL}$ hexane and then added to $2 \mathrm{~mL}$ NMF solution containing $10 \mu \mathrm{L}\left(\mathrm{NH}_{4}\right)_{2} \mathrm{~S}(40-48 \%)$ solution under Ar atmosphere. After ligands exchange, $\mathrm{CdSe} / \mathrm{S}^{2-}$ NPLs were transferred from hexane phase into NMF phase in the form of CdSe / $\mathrm{S}^{2-}$ NPLs. NPLs were washed twice with hexane and precipitated with ethyl acetate. The precipitates were dispersed into $2 \mathrm{~mL} \mathrm{NMF}$.

\section{(H) Fusion of $\mathrm{CdS} / \mathrm{Cd}^{2+}$ QDs and $\mathrm{CdSe} / \mathrm{S}^{2-} \mathrm{NPLs}$}

$128 \mu \mathrm{L}$ NMF solution of $\mathrm{CdS} / \mathrm{Cd}^{2+}$ QDs $(0.716 \mathrm{nmol})$ was added into a $4 \mathrm{~mL}$ vial and sonicated for 20 seconds. $100 \mu \mathrm{L}$ NMF solution of CdSe/S ${ }^{2-}$ NPLs $(0.009 \mathrm{nmol})$ was added under vigorously stirring. The mixture was stirred for $10 \mathrm{~min}$ before measurement, resulting into the fusion of $\mathrm{CdS} / \mathrm{Cd}^{2+}$ QDs and $\mathrm{CdSe} / \mathrm{S}^{2-} \mathrm{NPLs}$. The final product was called as CdS QD/CdSe NPLs.

\section{Measurements}

UV-Vis spectra were recorded on an Agilent Cary 5000 UV-Vis-NIR spectrometer and fluorescence spectra were acquired using a Horiba NanoLog spectrofluorometer with a $0.5-\mathrm{cm}$ quartz spectrophotometer cell. QY was calculated relative to a reference dye (fluorescein in $1 \mathrm{mM} \mathrm{NaOH}$, QY $=92 \%$ ). For fluorescence QY measurements, the absorbance for the standard sample and NPL samples at the 
absorption peak and the fluorescence spectra of the identical solutions excited at the wavelengths of the absorption peaks were measured. TEM images were obtained using a JEOL 2010 LaB6 high-resolution microscope in the Frederick Seitz Materials Research Laboratory Central Research Facilities at University of Illinois. Elemental analysis was performed using a PerkinElmer Optima 2000DV ICP-optical emission spectrometer.

\section{Referrence}

[1] O. Chen, X. Chen, Y. G. Yang, J. Lynch, H. M. Wu, J. Q. Zhuang, Y. C. Cao. Angew. Chem. Int. Ed. 2008, 47, 8638.

[2] Y. C. Cao, J. Wang, J. Am. Chem. Soc. 2004, 126, 14336.

[3] S. J. Lim, D. R. McDougle, M. U. Zahid, L. Ma, A. Das, A. M. Smith. J. Am. Chem. Soc. 2016, 138, 64.

[4] Z. Li, Peng, X. J. Am. Chem. Soc. 2011, 133, 6578.

[5] S. J. Lim, W. Kim, S. K. Shin. J. Am. Chem. Soc. 2012, 134, 7576.

[6] S. Ithurria, D. V. Talapin. J. Am. Chem. Soc. 2012, 134, 18585. 